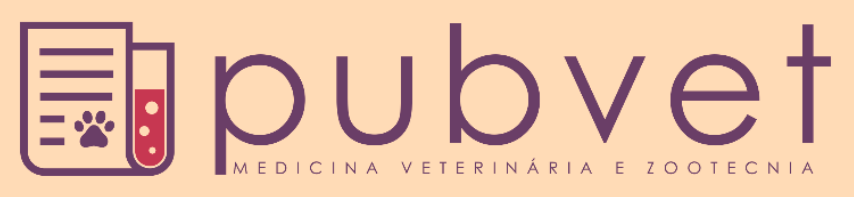

https://doi.org/10.31533/pubvet.v13n4a352.1-5

\title{
Avaliação sorológica de cães vacinados com vacinas comerciais contra leishmaniose visceral no município de Íuna - ES após um ano de vacinação
}

\author{
Yuri Vieira Almeida ${ }^{\bullet}$, Laisa Savergnini Poleze $^{1}{ }^{\bullet}$, Ligia Isabelle Silva Souza ${ }^{1}$, \\ Marcos Santos Zanini ${ }^{2 *} \bullet$
}

${ }^{I}$ Acadêmicos de Medicina Veterinária da Universidade Federal do Espírito Santo. Alegre - ES Brasil.

${ }^{2}$ Docente, Universidade Federal do Espírito Santo, Departamento de Medicina Veterinária. Alegre - ES Brasil

*Autor para correspondência: marcos.zanini@ufes.br

Resumo. O município de Íuna - ES é classificado como região endêmica para leishmaniose tegumentar americana e fronteiriça com regiões endêmicas para leishmaniose visceral do Estado de Minas Gerais. Quatorze cães identificados com chips numéricos subcutâneo foram vacinados com vacina comercial contra leishmaniose visceral ao final do ano de 2014, com três doses da respectiva vacina e não sendo revacinados durante o ano 2015. Estes cães foram monitorados durante o ano 2015 e nenhum animal desenvolveu quadro clínico para leishmaniose visceral ou tegumentar. Foi realizado o teste de ELISA com o soro destes animais frente aos antígenos de Leishmania (Viannia) braziliensis, Leishmania infantum chagasi e antígeno vacinal A2, e encontrou-se que $64,2 \%$ e $85,7 \%$ e $100 \%$ foram positivos frente aos respectivos antígenos. Assim também se conclui que pela técnica de ELISA indireta convencional com os antígenos utilizados não é possível diferenciar animais vacinados e animais assintomáticos, o que indica reação cruzada, pois os soros positivos para antígeno vacinal A2 também são positivos para antígenos de cultura de $L$. braziliensis e L. chagasi.

Palavras chave: ELISA, leishmaniose tegumentar, leishmaniose visceral, vacina

\section{Serological evaluation of dogs vaccinated with commercial vaccines against visceral leishmaniasis in the municipality of Íuna-ES after one year of vaccination}

\begin{abstract}
The municipality of Íuna - ES is classified as an endemic region for American tegumentary leishmaniasis and bordered with endemic regions for visceral leishmaniasis of the State of Minas Gerais. Fourteen dogs identified with subcutaneous numeric chips were vaccinated with a commercial vaccine against visceral leishmaniasis by the end of 2014 , with three doses of the respective vaccine and not being revaccinated during the year 2015. These dogs were monitored during the year 2015 and no animals developed clinical symptoms for visceral or tegumentary leishmaniasis. The ELISA test was performed with the serum of these animals against the antigens of Leishmania (Viannia) braziliensis, Leishmania infantum chagasi and A2 vaccine antigen, and it was found that $64.2 \%$ and $85.7 \%$ and $100 \%$ were positive antigens, indicating that the animals remain immunized. Thus, it is also concluded that the conventional indirect ELISA technique with the antigens used cannot differentiate vaccinated and asymptomatic animals, which indicates a cross reaction, since sera positive for A2 vaccine antigen are also partially positive for $L$. braziliensis and L. chagasi culture antigens.
\end{abstract}

Keywords: ELISA, tegumentary leishmaniasis, visceral leishmaniasis, vaccine 


\title{
Evaluación serológica de perros vacunados con vacunas comerciales contra leishmaniasis visceral en el municipio de Iuna - ES después de un año de vacunación
}

\begin{abstract}
Resumen. El municipio de Íuna - ES es clasificado como región endémica para leishmaniosis tegumentar americana y fronteriza con regiones endémicas para leishmaniasis visceral del Estado de Minas Gerais. Catorce perros identificados con chips numéricos subcutáneos fueron inmunizados con vacuna comercial contra leishmaniasis visceral al final del año 2014, con tres dosis de la respectiva vacuna y no siendo revacunados durante el año 2015. Estos perros fueron monitoreados durante el año 2015 y ningún animal desarrolló en el cuadro clínico para leishmaniasis visceral o tegumentar. Se realizó la prueba de ELISA con el suero de estos animales frente a los antígenos de Leishmania (Viannia) braziliensis, Leishmania infantum chagasi y antígeno vacunal A2, y se encontró que el $64,2 \%$, el $85,7 \%$ y el $100 \%$ fueron positivos frente a sus respectivos antígenos, indicando que los animales siguen inmunizados. Así también se concluye que por la técnica de ELISA indirecta convencional con los antígenos utilizados no es posible diferenciar animales vacunados y animales asintomáticos, lo que indica reacción cruzada, pues los sueros positivos para antígeno vacunal A2 también son parcialmente positivos para antígenos de cultivo de L. braziliensis y L. chagasi.
\end{abstract}

Palabras clave: ELISA, leishmaniasis tegumentar, leishmaniasis visceral, vacuna

\section{Introdução}

A leishmaniose é uma zoonose, de grande importância médica para o homem, causada por protozoários do gênero Leishmania que, dependendo dos fatores da espécie, influenciam a sua evolução e prognóstico da infecção. Dois fatores importantes estão envolvidos nesta situação, sendo a habilidade de algumas cepas de Leishmania serem resistentes aos efeitos microbicidas dos macrófagos ativados e sua capacidade de esquivar-se da resposta imune do hospedeiro, sendo que a resposta imune celular é considerada mais protetora do que a resposta humoral (Grimaldi \& Tesh, 1993).

De acordo com o Ministério da Saúde (Brasil, 2016), no ano de 2016 foram relatados 12.690 novos casos de leishmaniose tegumentar e 3.200 novos casos de leishmaniose visceral com respectivo coeficiente de detecção de 6,16 e 1,55 casos a cada 100.000 habitantes com maior incidência na região Norte e Nordeste, respectivamente.

O estudo das vacinas contra a leishmaniose vem ocorrendo devido aos avanços no esclarecimento dos mecanismos imunológicos que controlam a infecção. Esta espécie apresenta uma homologia genética antigênica com outras espécies de Leishmania, sendo assim, o uso de vacinas pan-Leishmania é sugerido (Carvalho et al., 2002; Mendonça et al., 2006; Pinheiro et al., 2018).

O objetivo do trabalho foi avaliar a resposta sorológica de cães vacinados frente à vacina comercial contra leishmaniose visceral na área de Íuna - ES depois de mais de um ano de vacinação utilizando a técnica de ELISA indireta, visto que esta técnica apresenta alta sensibilidade para a determinação de anticorpos para Leishmania spp. (Barroso-Freitas et al., 2009; Madeira et al., 2003; Ribeiro et al., 2007), sendo utilizados antígenos de Leishmania (L.) chagasi, Leishmania (Viannia) braziliensis e antígeno vacinal composto de proteína recombinante $\mathrm{A} 2$, oriunda de $L$. donovani proveniente da própria vacina comercial.

\section{Material e métodos}

Quatorze cães identificados com chips numéricos subcutâneo foram vacinados com vacina comercial contra leishmaniose visceral ao final do ano de 2014, com três doses da respectiva vacina e não sendo revacinados durante o ano 2015. Estes cães foram monitorados durante o ano 2015 e nenhum animal desenvolveu quadro clínico para leishmaniose visceral ou tegumentar. No ano 2016 foi coletado, em tubos contendo EDTA, o sangue dos 14 cães imunizados. Estes tubos foram centrifugados a 1,500g por 5 minutos, dessorados e armazenados a $-20^{\circ} \mathrm{C}$ até a utilização para a técnica de ELISA indireta. 
Foram cultivadas amostras de L. (V.) braziliensis (MHOM/BR/75/M2903) e L. (L.) chagasi (MHOM/BR/1974/PP75) em meio de cultura Schneider's Insect Medium Sigma ${ }^{\circledR}$ em estufa BOD na temperatura de $25^{\circ} \mathrm{C}$. Dessas amostras, foram extraídos antígenos solúveis segundo Ribeiro et al. (2007), usando ciclos de congelamento e descongelamento e técnica de sonicação na fase estacionária da cultura. Para o antígeno vacinal, a parte liofilizada foi reconstituída conforme a recomendação do fabricante, seguido da adição da vacina reconstituída em um novo frasco de vacina, permitindo uma solução $2 \mathrm{X}$ concentrada. Em seguida, foi feita a centrifugação a 15,000g por uma hora e coleta do sobrenadante.

Foi utilizado a técnica modificada de ELISA indireta segundo Ribeiro et al. (2007) resumidamente abaixo descrita para detectar anticorpos vacinais na presença de antígeno de L. chagasi, L. braziliensis e fração solúvel vacinal, fixados em placas de poliestireno com 96 poços. Para antígeno de Leishmania chagasi, L. braziliensis e Ag. vacinal foram utilizadas a concentração de $0.7,0.13$ e $0.2 \mathrm{mg} / \mathrm{mL}$, respectivamente, diluídos em tampão carbonato-bicarbonato, $\mathrm{pH} 9.6$, em uma proporção de 1:100. A técnica consistiu em fixar o antígeno solúvel nos poços da placa por 12 horas a $4^{\circ} \mathrm{C}$ seguido de lavagem (4x) com solução de $\mathrm{NaCl}$ e $0.05 \%$ Tween 20 . Após a etapa de fixação foi realizado o bloqueio contendo $616 \mu \mathrm{L}$ soro fetal bovino (SFB) e $10 \mathrm{~mL}$ de PBS-1X para evitar reações inespecíficas com $100 \mu \mathrm{L} /$ poço desta solução e incubado por 45 minutos à $37^{\circ} \mathrm{C}$. A seguir, lavou-se 2 vezes com solução tampão de lavagem. Em seguida foi adicionado os soros caninos a serem avaliados no volume de $100 \mu \mathrm{L} /$ poço diluídos a 1:40 em PBS-T. Após 45 minutos de incubação à $37^{\circ} \mathrm{C}$ as placas foram lavadas cinco vezes e em seguida foram adicionados $100 \mu \mathrm{L} /$ poço de anti- $\operatorname{IgG}$ de cão conjugada à peroxidase (Sheep anti-dog IgG2 HRP conjugated) (A40-121P, Bethyl Laboratory Inc., Montgomery, TX) diluída a 1:5000 em PBST. Após incubação por 45 minutos à $37^{\circ} \mathrm{C}$, foram realizadas novamente cinco lavagens. A revelação foi feita com $100 \mu \mathrm{L}$ /poço de solução contendo $2 \mu \mathrm{L}$ de peróxido de hidrogênio (H2O2) a $30 \%$ e $1 \mathrm{mg}$ de orto-fenilenodiamina (OPD/SIGMA) em $10 \mathrm{~mL}$ de tampão citrato-fosfato (ácido cítrico - C6H8O7; fosfato de sódio dibásico - Na2HPO4) pH 5,0 com incubação à $37^{\circ} \mathrm{C}$ por 10 minutos. A reação é interrompida após os 10 minutos com $32 \mu \mathrm{L}$ de solução de $\mathrm{H} 2 \mathrm{SO} 42,5 \mathrm{M}$ por poço e a placa lida imediatamente em espectrofotômetro em comprimento de onda de $490 \mathrm{~nm}$. A determinação da reatividade baseou-se em leituras superiores ao ponto de corte (cut off) calculado como a média da densidade ótica dos soros de 3 cães negativos (controles negativos) mais duas vezes o desvio-padrão da densidade ótica desses soros (Tannus et al., 2007). As análises estatísticas finais foram feitas usando o teste $T$ em um nível de significância de 0.05 .

\section{Resultados e discussão}

Para os diferentes antígenos utilizados na técnica de ELISA foram feitas as médias da absorbância das triplicatas das amostras e analisadas de acordo com o ponto de cut-off para determinar se é positivo ou negativo, sendo o cut-off $0.313,0.359$ e 0.339 para o antígeno de L. braziliensis, L. chagasi e vacinal, respectivamente. Em todos os testes foram utilizados soros de animais infectados por LTA como controles positivos. Os resultados finais e absorbâncias apresentam-se nas tabelas 1 e 2 . Devemos inicialmente considerar que todos os animais foram vacinados e que eventualmente podem ter sofrido desafio natural por $L$. braziliensis no ambiente vinculado por flebotomíneos infectados, logo, para haver resultados mais precisos, os animais deveriam permanecer em ambientes controlados, entretanto não deveriam reagir frente a $L$. chagasi uma vez que não existe registro desta forma da enfermidade na região ou mesmo a presença do flebotomíneo tradicionalmente transmissor.

Inicialmente, a partir dos resultados obtidos, verificou-se que no uso do antígeno de L. braziliensis e L. chagasi, $64,2 \%$ e $85,7 \%$ foram positivos, respectivamente, enquanto que $100 \%$ dos animais foram positivos frente ao antígeno vacinal. Primeiramente, isto indica que todos os animais testados ainda estão imunizados depois de um ano de vacinação.

Ademais, isto também mostra uma maior presença de epítopos comuns entre antígenos vacinais e $L$. chagasi, visto que a vacina é pretendida para uma proteção contra leishmaniose visceral. Além disso, a sequência gênica da proteína A2 não se encontra em L. braziliensis (Ghedin et al., 1997).

Três dos cinco animais negativos no ELISA para o antígeno L. braziliensis apresentaram-se positivos no ELISA com antígeno L. chagasi $(60 \%)$, do qual a densidade óptica de L. chagasi se apresentou numericamente maior, mas estatisticamente irrelevante $(\mathrm{P}=0,26)$. Isto mostra que o antígeno de $L$. 
chagasi apresentou maior sensibilidade no teste de ELISA para os animais vacinados, pelo mesmo motivo já discutido no parágrafo anterior.

Tabela 1. Resultados da técnica de ELISA frente aos três antígenos.

\begin{tabular}{ccccccc}
\hline Amostra & $\begin{array}{c}\text { Absorbância } L . \\
\text { braziliensis }\end{array}$ & $\begin{array}{c}\text { Resultado } L . \\
\text { braziliensis }\end{array}$ & $\begin{array}{c}\text { Absorbância } L . \\
\text { chagasi }\end{array}$ & $\begin{array}{c}\text { Resultado } L . \\
\text { chagasi }\end{array}$ & $\begin{array}{c}\text { Absorbância Ag. } \\
\text { Vacinal }\end{array}$ & $\begin{array}{c}\text { Resultado Ag. } \\
\text { vacinal }\end{array}$ \\
\hline 1 & $0.931 \pm 0.021$ & Positivo & $0.956 \pm 0.053$ & Positivo & $1,213 \pm 0.042$ & Positivo \\
2 & $0.443 \pm 0.035$ & Positivo & $0.676 \pm 0.052$ & Positivo & $0.683 \pm 0.026$ & Positivo \\
3 & $0.171 \pm 0.024$ & Negativo & $0.439 \pm 0.031$ & Positivo & $0.716 \pm 0.077$ & Positivo \\
4 & $0.364 \pm 0.029$ & Positivo & $0.421 \pm 0.009$ & Positivo & $0.833 \pm 0.108$ & Positivo \\
5 & $0.321 \pm 0.029$ & Positivo & $0.745 \pm 0.037$ & Positivo & $0.649 \pm 0.078$ & Positivo \\
6 & $0.744 \pm 0.039$ & Positivo & $0.732 \pm 0.047$ & Positivo & $1,119 \pm 0.041$ & Positivo \\
7 & $0.196 \pm 0.026$ & Negativo & $0.649 \pm 0.032$ & Positivo & $0.863 \pm 0.004$ & Positivo \\
8 & $0.329 \pm 0.036$ & Positivo & $0.651 \pm 0.048$ & Positivo & $0.515 \pm 0.050$ & Positivo \\
9 & $0.183 \pm 0.042$ & Negativo & $0.481 \pm 0.050$ & Positivo & $0.551 \pm 0.026$ & Positivo \\
10 & $0.215 \pm 0.014$ & Negativo & $0.266 \pm 0.003$ & Negativo & $0.433 \pm 0.030$ & Positivo \\
11 & $0.460 \pm 0.068$ & Positivo & $0.574 \pm 0.043$ & Positivo & $0.683 \pm 0.046$ & Positivo \\
12 & $0.618 \pm 0.099$ & Positivo & $0.654 \pm 0.058$ & Positivo & $0.985 \pm 0.129$ & Positivo \\
13 & $0.656 \pm 0.048$ & Positivo & $0.909 \pm 0.059$ & Positivo & $1,115 \pm 0.010$ & Positivo \\
14 & $0.267 \pm 0.060$ & Negativo & $0.330 \pm 0.011$ & Negativo & $0.487 \pm 0.060$ & Positivo \\
\hline
\end{tabular}

Média da densidade óptica à $595 \mathrm{~nm} \pm$ desvio padrão da média.

Tabela 2. Resultados condensados dos testes de ELISA.

\begin{tabular}{lll}
\hline Antígeno & Positivos & Negativos \\
\hline L. braziliensis & $9(64,2 \%)$ & $5(35,7 \%)$ \\
L. chagasi & $12(85,7 \%)$ & $2(14,3 \%)$ \\
Ag. vacinal & $14(100 \%)$ & $0(0 \%)$ \\
\hline
\end{tabular}

\section{Conclusão}

Primeiramente, conclui-se que todos os animais testados ainda estão imunizados depois de um ano de vacinação. Entretanto, com o resultado encontrado desta reatividade cruzada entre o antígeno vacinal A2 e as duas espécies de Leishmania usadas, constata-se que o teste utilizado não consegue diferenciar animais vacinados de infectados, e, dessa forma, opõe à informação do fabricante da vacina, afirmando que animais imunizados não produzem resposta sorológica frente aos testes de ELISA indireto rotineiros para diagnóstico de leishmaniose. Portanto, é fundamental que o animal vacinado seja devidamente registrado, pois posteriormente ao fazer um teste de ELISA indireto convencional com os antígenos de L. braziliensis ou $L$. chagasi, este animal será falsamente considerado infectado assintomático. Entendemos que para dirimir dúvidas entre animais vacinados ou assintomáticos, particularmente para L. chagasi, uma alternativa seria o uso de antígenos mais específicos ou testes moleculares, como a Reação em Cadeia da Polimerase.

\section{Referências bibliográficas}

Barroso-Freitas, A. P. T., Passos, S. R. L. \& Mouta-Confort, E. (2009). Accuracy of an ELISA and indirect immunofluorescence for the laboratory diagnosis of American tegumentary leishmaniasis. Transactions of the Royal Society of Tropical Medicine and Hygiene, 103383-389.

Brasil (2016), Ministério da Saúde, Secretaria de Ciência, Tecnologia e Insumos Estratégicos, Departamento de Assistência Farmacêutica.

Carvalho, F. A., Charest, H., Tavares, C. A., Matlashewski, G., Valente, E. P., Rabello, A., . . . Fernandes, A. P. (2002). Diagnosis of American visceral leishmaniasis in humans and dogs using the recombinant Leishmania donovani A2 antigen. Diagnostic Microbiology and Infectious Disease, 43289-295. 
Ghedin, E., Zhang, W. W., Charest, H., Sundar, S., Kenney, R. T. \& Matlashewski, G. (1997). Antibody response against a Leishmania donovani amastigote-stage-specific protein in patients with visceral leishmaniasis. Clinical and Diagnostic Laboratory Immunology, 4530-535.

Grimaldi, G. \& Tesh, R. B. (1993). Leishmaniases of the New World : Current concepts and implications for future research. Clinical Microbiology Reviews, 6230-250.

Madeira, M. D. F., Uchoa, C. M. A. \& Leal, C. A. (2003). Leishmania (Viannia) braziliensis em cães naturalmente infectados. Revista da Sociedade Brasileira de Medicina Tropical, 36551-555.

Mendonça, L. Z., Resende, L. A., Lanna, M. F., Aguiar-Soares, R. D., Roatt, B. M., Castro, R. A., . . . Giunchetti, R. C. (2006). Multicomponent LBSap vaccine displays immunological and parasitological profiles similar to those of Leish-Tec ${ }^{\circledR}$ and Leishmune ${ }^{\circledR}$ vaccines against visceral leishmaniasis. Parasites \& Vectors, 9472-484.

Pinheiro, J. A., Giori, S. G., Almeida, S. L. H., Souza, R. A., Madureira, A. P. \& Zanini, M. S. (2018). Cães vacinados para leishmaniose visceral respondem sorologicamente aos antigenos de Leishmania braziliensis. Ciências Agrárias, 39573-582.

Ribeiro, F. C., Schubach, A. O. \& Mouta-confort, E. (2007). Use of ELISA employing Leishmania (Viannia) braziliensis and Leishmania (Leishmania) chagasi antigens for the detection of IgG and IgG1 and IgG2 subclasses in the diagnosis of American tegumentary leishmaniasis in dogs. Veterinary Parasitology, 148200-206.

Tannus, M. M., Rodrigues, F. H., Mastrantonio, E. C., Rocha, F. A., Pereira, C. G., Silva, A. L. N. \& Souza, M. A. (2007). Reatividade sorológica de cães frente a antígenos de três espécies de Leishmania. Horizonte Científico, 11-28.

Recebido: 30 de abril, 2019.

Aprovado: 27 de maio, 2019

Publicado: 30 de junho, 2019.

Licenciamento: Este artigo é publicado na modalidade Acesso Aberto sob a licença Creative Commons Atribuição 4.0 (CC-BY 4.0), a qual permite uso irrestrito, distribuição, reprodução em qualquer meio, desde que o autor e a fonte sejam devidamente creditados. 